Tarih Kültür ve Sanat Araştırmaları Dergisi

Revue des Recherches en Histoire Culture et Art

مجلة البحوث التاريخية والثقافية والفنية
Vol. 7, No. 3, September 2018

Copyright (C) Karabuk University

http://kutaksam.karabuk.edu.tr

\title{
DOI: 10.7596/taksad.v7i3.1540
}

Citation: Kaspour, H., Chareie, A., Asadi, M., \& Haseli, P. (2018). Investigating the Effects of Technology on Nastaliq Script. Journal of History Culture and Art Research, 7(3), 724-733. doi:http://dx.doi.org/10.7596/taksad.v7i3.1540

\section{Investigating the Effects of Technology on Nastaliq Script*}

\author{
Hoda Kaspour ${ }^{1}$, Abdolreza Chareie ${ }^{2}$, \\ Morteza Asadi ${ }^{3}$, Parviz Haseli ${ }^{4}$
}

\begin{abstract}
Calligraphy, since its formation, has witnessed an innovative transformation. Developments in the printing industry have significantly influenced its evolution. In script work, speed and accuracy have always been important elements; however, the existence of technological tools has led to a significant number of calligraphic tasks without calligraphist. The main purpose of this research is to explain the changes brought by the use of technological tools in calligraphy. The contradiction or coordination of traditional aspects of calligraphy with different dimensions of technology and the concern for the collapse of calligraphy by this phenomenon necessitates this research. In today's world, writings are created by technological tools with special software features in cyberspace, and the letters and words are combined with the same principles and rules of traditional writing in the computer environment. The factors that led calligraphy to change in technology are the main issues in this research.
\end{abstract}

Keywords: Calligraphy, Technological writings, Nastaliq script.

\footnotetext{
* This paper extracted from Hoda Kaspour's PHD thesis: The Study of The relation between Technological Writings and Calligraphy with emphasis on Nastaliq script.

${ }^{1}$ Ph.D. student of Art Research, Faculty of Art, Shahed University. E-mail: hodakaspur@gmail.com

${ }^{2}$ Faculty Member of Shahed University Faculty of Art. E-mail: chareie@shahed.ac.ir

${ }^{3}$ Faculty Member of Shahed University Faculty of Art. E-mail: asadi@shahed.ac.ir

${ }^{4}$ Faculty Member of Shahed University Faculty of Art. E-mail: haseli@shahed.ac.ir
} 


\section{Introduction}

Technology, with the creation of attractive computer effects, has, to a certain extent, replaced the apparent beauty of the intrinsic and spiritual beauty, and on the other hand, in response to the large volume of society's needs for calligraphy, two categories of "speed in writing" and "identical writing" which is the guarantor of the preservation and survival of the line (script), is located in front of the uniformity (monotony) of writing.

From the aspects of technology exposure with the most important tool of traditional calligraphy -that is pen (font) and its functions are identical writing, writing speed and uniformity. The true sanctity of calligraphy and everything that has spiritual body placed in the space and place of paper and pen (font). Therefore, there are clear differences between the traditional calligraphic work by calligraphist artist who has worked for many years and the work produced by the computer. But given the fact that new phenomena such as technology in the form of calligraphic software are based on traditions, and because every entity tends to stay and live, modern and traditional phenomena can live along with each other and the art of calligraphy has the ability to be casted in both modern and traditional "casting".

The point that matters here is the contradiction or coordination of the sacred aspect of calligraphy with various aspects of technology and the concern about the diminution of the sacred dimension of this art through this phenomenon. In connection with this, Mitra Manavi Rad writes in the book of The Position of Calligraphy in the Era of Technology: "Calligraphy in Iran reflects on spirituality and simplicity, the art of communication, silence, being together and living together, art with high dimensions and values, that we must step into the revelation of each of these dimensions, and return to the principle of non-trimming and abstraction." (Manavi Rad, 2006, p.123). Annemarie Schimmel, in her book title Calligraphy and Islamic Culture, says: "The observance of the principles and the structure of calligraphy can be accompanied by the beauty of the line (script) and its connection with the holy world." (Schimmel, 1989, p.30). Seyyed Hossein Nasr in the book Knowledge and Spirituality emphasizes on tradition, calligraphy and its relation to holiness, and says: "Islamic calligraphy and tradition are closely related to each other, the tradition has an unbreakable link with revelation, religion, with a sacred meaning, with the concept of right thinking, with authority, continuity and discipline in transmitting the truth, by the appearance and the inner being, as well as by spiritual life, and finally with science and art" (Nasr, 2001, p.147). Also, Leily Baratzadeh in the book Calligraphy in Iran notes that "the technology and the arrival of software put the contemporary calligraphy on a two way path, selection of which indicates that the calligrapher has remained loyal to the same classical and traditional principles, or has left the principles and rules of the line (script), or even without these, he/she become the innovator of a new style and way" (Baratzadeh, 2005, p.97).

This research emphasizes the quality of the good line (script) (calligraphy) in the field of technology and examines the changes brought by the use of technological tools. So the main question in this research is that what are the changes from the use of technological tools in calligraphy?

Calligraphy in the special sense is the art of fine writing. This term applies to free writing with a brush or pencil (Pakbaz, 2004, p.207). Calligraphy is also the beautiful painting of letters and words based on certain principles and rules (Rashvand, 2005, p.1).

The word technique has a French root and in the broad sense refers to industry, science, art and profession. It is also referred to as "technology" and the science of technique and industry (Rahbarnia, 2006, p.102), and it can also be pointed out that the science lies within the technology: "The application of knowledge based on systematic science and knowledge to conduct practical affairs by systematic systems of people, organizations, objects and machines" (Peasy, 1988, p.10). The quantity in human societies has led to an increasing need for technology development. That part of the technology that moves in line with nature does not conflict with sacredness, and in contrast, technology in confronting nature is definitely harmful to 
the human body and soul and disrupts its evolutionary development (Rahbarnia, 2006, p.102). It is possible to point out the connection between technology and the Nastaliq line (script), which has been the special Iranian art of the past, so far. The Nastaliq line (script) has come to the virtual world where speed and accuracy have led to the generalization of examples of the Nastaliq line (script) in the social realm. The existence of computer software systems such as the software-Celk (based on Abbas Akhavin's line [script]) and the Chalipa and Miremad software (based on the Amir Ahammad Falsafi's line [script]) have resulted in a considerable number of calligraphic issues done without the presence of calligraphers and the conditions and atmosphere of creation of the work traditionally. Of course, while reducing calligraphy orders, it has facilitated and expanded the use of usage patterns (Teimoori, 2010, p.94).

The technological tool in its particular sense is used in this research, and includes the range of computers and software and fonts that can be used to write traditional lines (scripts) (Figures 1 and 2).

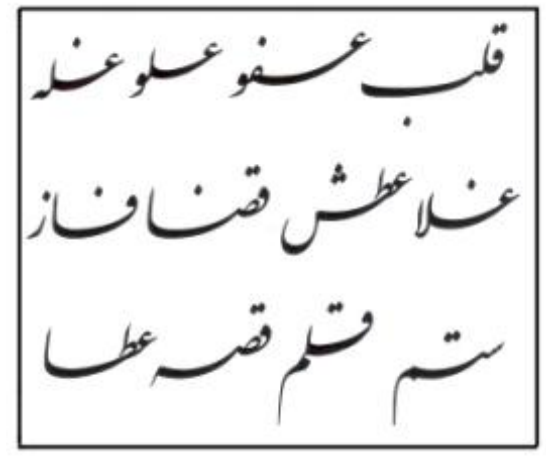

Figure 1. Words written with Iran Nastaliq script

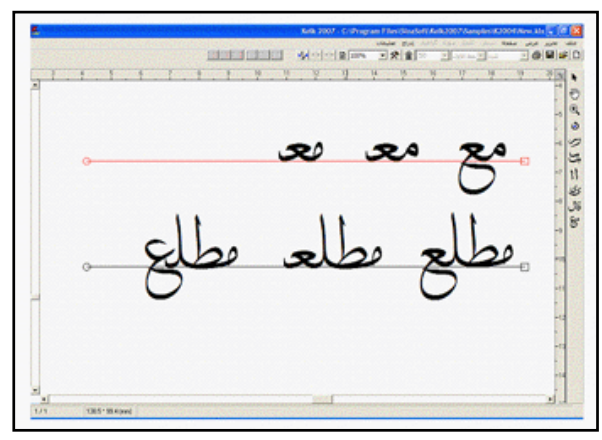

Figure 2. Third (Solth) compounds in Celk Software

In this research, three criteria for qualitative study of the line (script) and its changes through the technological tool have been investigated (Table 1):
A: Identical writing
B: Speed in writing
C: Uniform (monotonous) writing

Table 1. Qualitative variables design

\begin{tabular}{|c|}
\hline Variables design \\
\hline Identical writing \\
\hline Speed in writing \\
\hline Uniform (monotonous) writing \\
\hline
\end{tabular}




\section{A: Identical writing}

Habibullah Fazaeli, in the book of the teachings of the line (script), states: "Good and bad spirits afflict the scribes, and with psychological and physical influences, the calligraphist's line (script) changes in terms of beauty; so a beautiful line (script) based on the principles of calligraphy, is not found in all the work of a calligrapher, and it has also been pointed out that the environment and atmospheric conditions, such as clean nature and air, make the calligraphist's talent and artistic gift fertile and this passion appear in the quality of his/her line" (Fazaeli, 2006, p.51).

If a calligrapher can provide the same conditions physically and emotionally, it is not possible to evenly equalize in all monomer lines with a pen.

If a calligrapher can provide the same conditions physically and emotionally, then absolute identical writing (equivalence) can't be possible in all the units of the line (script) with the pencil.

If the calligrapher, in terms of the same and equal terms, repeats (writes) a sentence several times, it is seen that all of them are equal in terms of principles and rules, but differ in detail (Table 2).

Table 2. Lack of absolute identical writing (homogeneity in the composition) in traditional writing

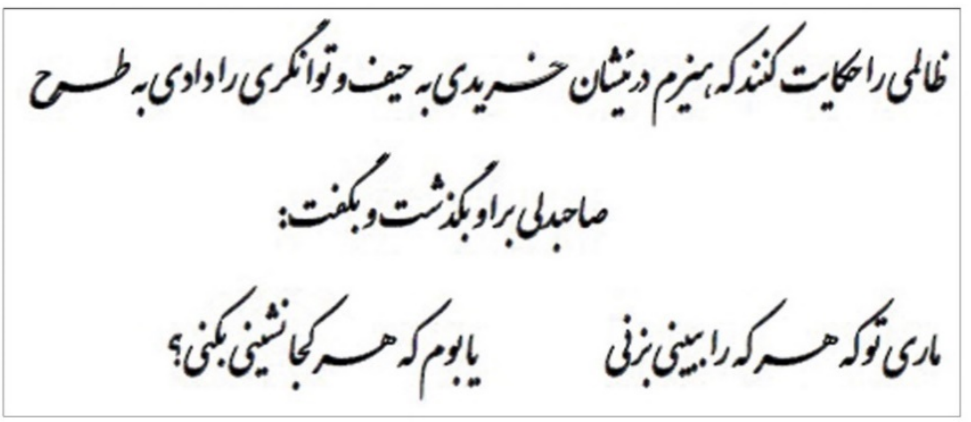

writing in a traditional manner, calligraphist: Amir Falsafi.Source (Falsafi, 1999, 50)

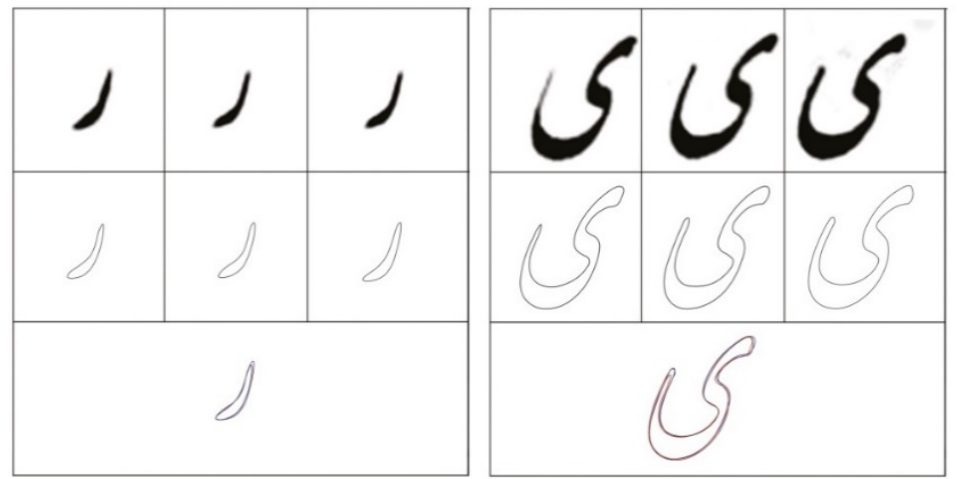

A comparative comparison of the lack of identical writing in the singular letters of " $\checkmark$ " and " $\nu$ " in the traditional writing through the overlying of letters.

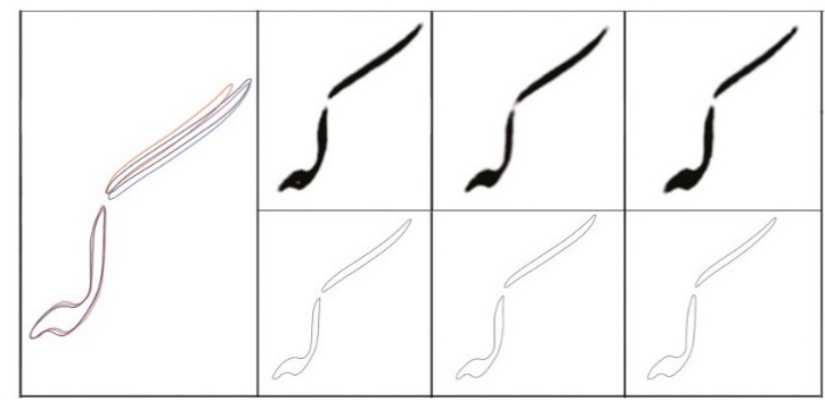

A comparative comparison of the lack of identical (homogeneity in the composition) of "ऽ" in the traditional writing through the overlying of letters. 
The technology without interference of the environment and the user's mental and physical influences through the lines (scripts) ready in the program creates the same quality of work, which, due to the medium quality of computer lines, the calligraphy retains in the same medium level of quality and it's not possible to change the quality of the line much higher and also its qualitative descent. However, the principle of proportionality, which is the guarantor of identical writing of line (script), is adhered to in the design of technological tools (Table 3).

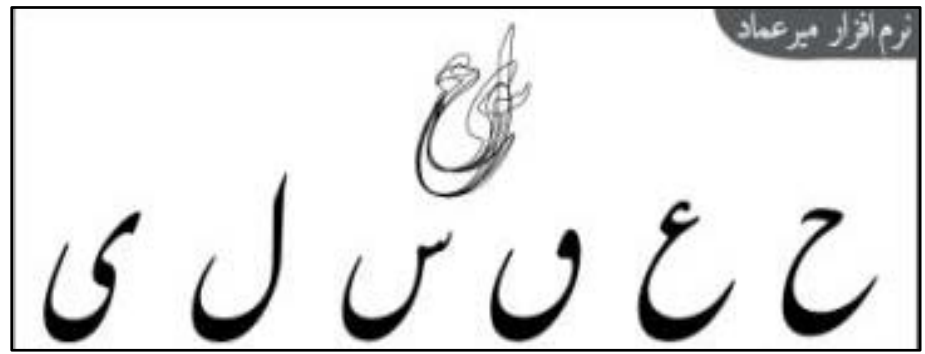

Figure 3. Observance of the proportionality rule in the identical writing of circle letters in the Miremad software

Table 3. Absolute identical writing (homogeneity in the composition) with the technological tool

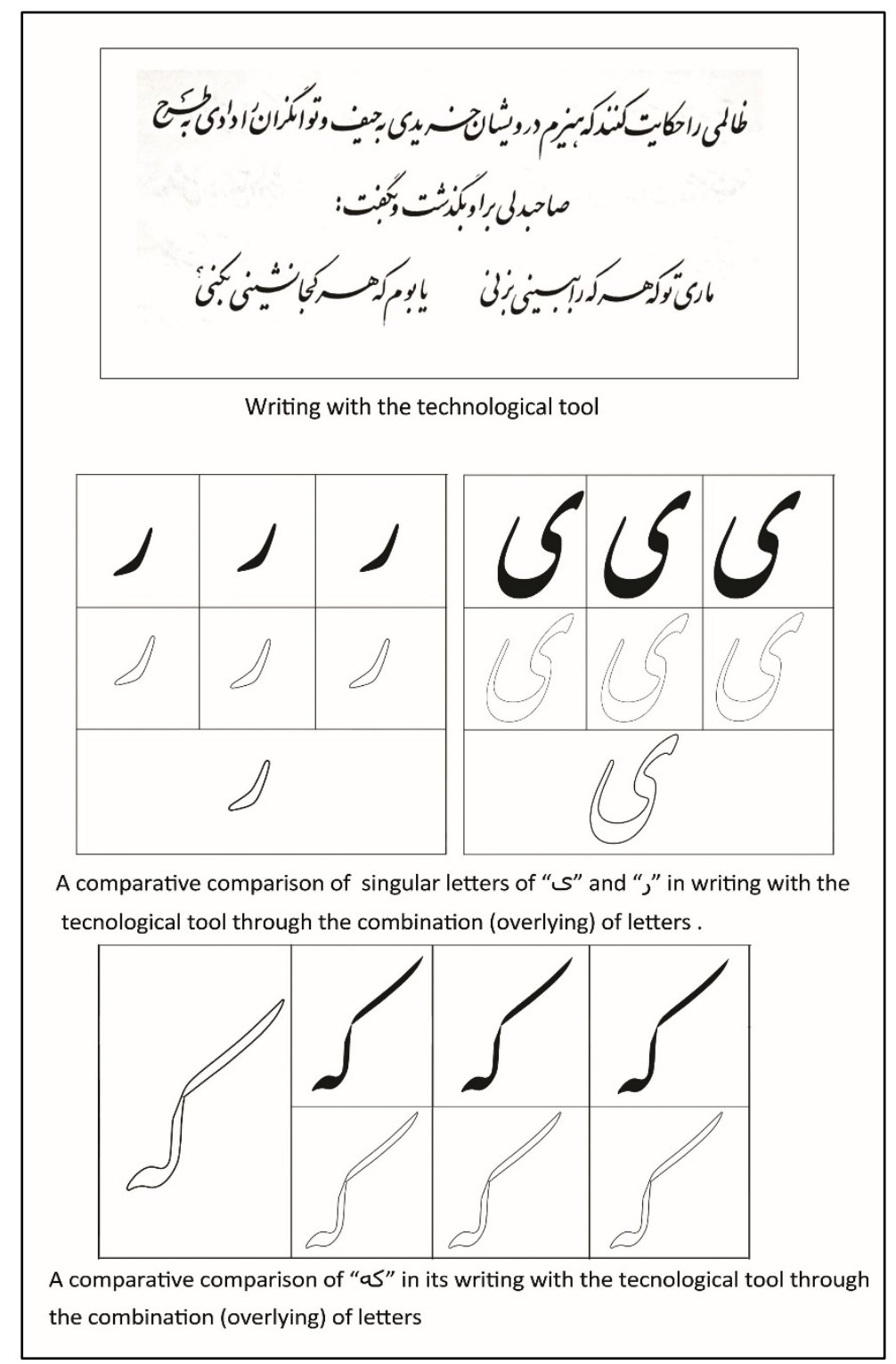




\section{B: Speed in writing}

\section{In the context of the competition (writing)}

Since the beginning of the 11th century and the end of the Safavid period, the broken line (script) of Nastaliq was due to the proliferation of applications and the need for speed writing was emerged. The most famous calligraphist of this line is Dervish Abdul Majid Taleghani (1170-1185 AH). Inventing and extracting the broken line (script) of Nastaliq from Nastaliq in the early eleventh century attributed to Morteza Gholikhan Shamloo and some to Mohammad Shafi Heravi, known as Shafia. This kind of calligraphy, has various forms of beauty. Moving on this line is freer than Nastaliq. Even though the Nastaliq line was originally devised for the need for speed writing, but its twisty movements hurt its readability and failed to fulfill its mission. In the contemporary era, broken Nastaliq's is mainly used to write Persian poetic texts.

On the other hand, if a calligrapher can provide the same physical and emotional (psychological) conditions for writing, it is not possible to make absolute identical writing (homogeneity in the composition) in all units of the line. As mentioned, if the calligrapher, in the same conditions, writes a sentence several times, it is again seen that they are all equal in terms of principles and rules, but they differ in detail, which is understood by experts and technicians (ibid, 51). In this regard, the function of calligraphy software can be better evaluated than traditional calligraphy; for example, when writing to a fine line (calligraphy) on several pages or several hundred pages, writing in a traditional manner with full compliance of identical writing (homogeneity in the composition), is impossible due to the change in mental and physical conditions as well as the atmospheric conditions and the environment in which the calligrapher is constantly engaged in writing. While technological tools, without the intervention of these factors, have the ability to write in high volume at high speed and in a small amount of time (Figure 4).

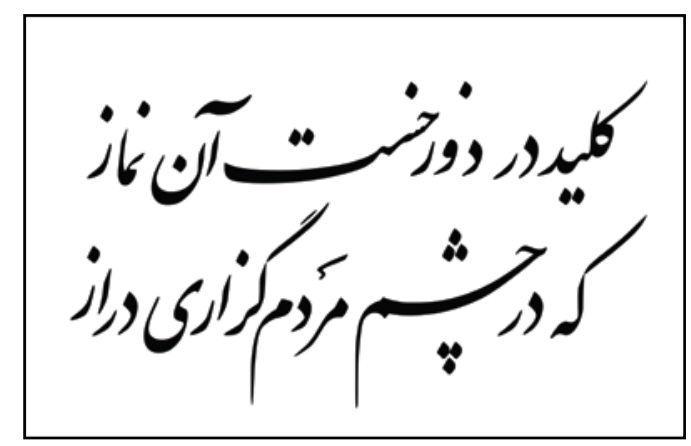

Figure 4. Line writing (interlineations) in the context of technology

For better understanding, it is possible to highlight a text that has been written in volumes and needs to be converted into a calligraphy text. For this purpose, using one of the fonts, the text can be converted into calligraphy text.

\section{In the context of two lines cross scripting and Chalipa}

Two rows cross scripting through technological tools is far more convenient than calligraphy in the traditional way because the inter-row settings are done with less time and more precision, and the user can by turning the letters and dragging each letter and then restoring it to the first condition, use the best mode for writing two rows writing. 
Among other things, it is worth noting that the ease of implementation of the principles of Chalipa writing through the technological means through auto- measurements of written tilt and alignment of the written lines.

The technological instrument of the various lines, which may be irregular and heterogeneous in terms of the shape and geometry of letters and words, gives fitness and tone in a collection called Chlipa; without the combination of the golden ratios found in the Chlipa to be fade; in addition in one set, in all four rows, the common relations, like the continuous chain, maintain their unity and continuity (Figure 5).

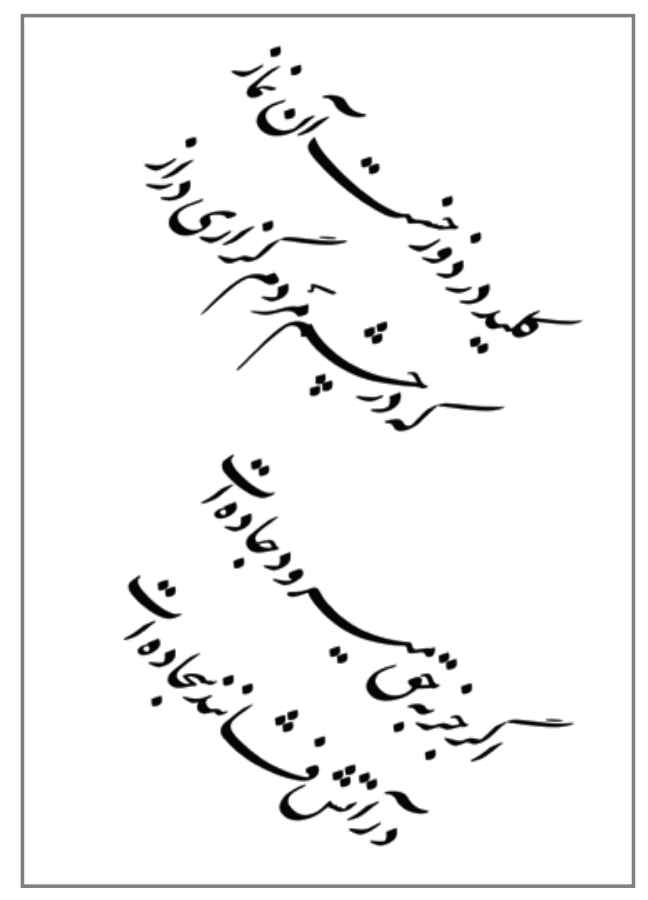

Figure 5. Chalipa sample using a technological tool

\section{C: Uniform (monotonous) writing}

The meaning of this term represents a kind of consistent and boredom style in a technological writings. Technological writings are limited to the script (line) patterns of some calligraphers, which, due to applicability in software, many of its delicacies and beauty are lost due to machining, and despite the fact that the line (script) of contemporary experts is the illustration of oldest and calligraphy's predecessors, but because of the obstacles that arise in the process of turning the line (script) into a technological tool on a computer, the old-fashioned calligraphy is completely and precisely has been illustrated in it.

In traditional calligraphy, the difference in styles makes it possible for each line (script) to find the color and smell of its creator and to look more alive and diverse. Each professor has his/her own style, the essence of which distinguishes him/her from other. In traditional calligraphy, the method of practicing has stages and the goal of passing these stages is achieving in a different manner in a calligrapher's line (script).

These steps include:

Theoretical practice: The student must carefully look at his teacher's line (script) and direct his/her mind and soul towards the spiritual qualities of the line (script).

Pencil practice: This is writing on the (according to) teacher's line (script), after theoretical practice, for a while, he/she writes those monomers exactly like the master's line (script). 
Fictitious practice: Without the mere imitation of the master's line (script), become the owner of the capture and expert on the technical and aesthetic points of line (script) (Ebrahimi, 1969, p.147).

Knowledge of calligraphy and the relation between its different styles depends on the exact recognition of the compositions and the components of the calligrapher's line (script). The need for full mastery of the letter designer to the traditional calligraphy principles and the provision of new programming approaches in order to better represent the effects of traditional lines on a computer can reduce the line (script) uniformity (monotonous) on the computer, and the letter designer should also be governed by calligraphy rules, meaning that his/her mind must seek to analyze and select the best form of letters in technological appearance.

The analysis and selection performed in the execution of the letters on the computer is exquisite in terms of the outer shell, which contains the observance of traditional calligraphy principles and conventions in terms of maintaining the line's (script's) survival, but the main problem is the maintenance of the inner layers of effect of the line (script) through the presentation of style of calligraphy on the computer. To understand this, one can refer to the line (script) pattern of one of the computer writing fonts.

For example, Celk software, as one of computer writing tools for Nastaliq, is the propagator of contemporary calligrapher -Abbas Akhavin's line (script). This calligrapher is one of the mimics of the calligraphy method of Mir'emad al-Hassani Qazvini. In a comparative comparison in the units and combinations between this calligrapher's line (script) and Miremad's line (script), the manner of the calligrapher has been determined. But noteworthy is the presentation of Abbas Akhavin's line (script) in computer, which is somewhat similar to the original style. Technology seems to be incapacitated in addressing the delicacies and features that are characteristic of the Akhavin's style (Table 4).

Table 4. A comparative comparison of calligrapher's line (script) style with the oldest calligrapher's line (script) and its representation in the software

\begin{tabular}{|c||c|c|}
\hline Miremad's style & $\begin{array}{l}\text { Abbas's } \\
\text { Akhavin's style }\end{array}$ & $\begin{array}{l}\text { Abbas Akhavin's script } \\
\text { in Celk software }\end{array}$ \\
\hline & & \\
\hline & & \\
\hline
\end{tabular}


Table 5. Combination of Basmellah ${ }^{5}$ created using graphical software in the virtual environment.

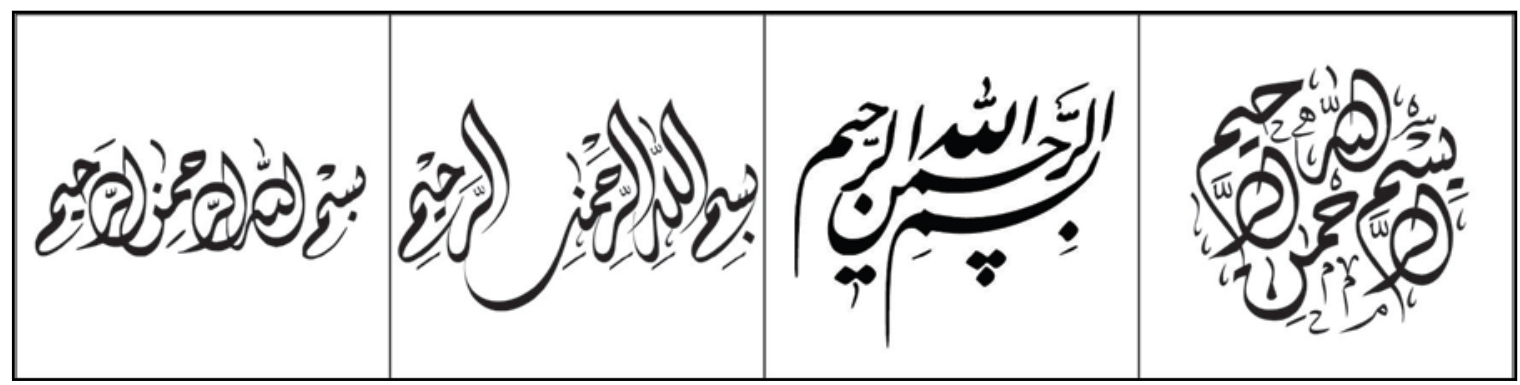

In these examples, the reflection of technology with the industrial approach and technical skills outside the quality dimension of the line (script) has been considered.

\section{Conclusion}

With the design of the variables, the differences between the technological tool and the calligraphy were determined. In traditional calligraphy, when the line (script) fulfilled its mission of understanding and influence, creates a space that is beautiful. When, due to computer effects, the calligraphic effect, as an ornamental element is formed solely to create an appealing and intrinsic spiritual appearance, inevitably, in technological writings, visual effects are more pronounced than line (script). Technology has prompted the rapidity of writing, along with the identical writing (homogeneity of composition) in units and compounds, can respond to the massive volume of requests and market needs for calligraphy and writing. But on the contrary, the two categories of "speed in writing" and "identical writing (homogeneity of composition)", which are specific to the technological tool, uniformity in writing (the lack of variety in style of line [script]) can be of the most important damage to the aesthetics of calligraphy in the context of technology.

At the moment, it is necessary that both groups, calligraphy artists and computer program specialists, are more connected with the qualitative and technical dimensions of calligraphy due to the use of new methods and tools that are necessary for the technology age and take effective steps to expand the capabilities of calligraphy through technology facilities.

On the other hand, due to the general interest in terms of style and quality improvement of the line (script), as well as the placement of calligraphy in the orbit of globalization, important moves such as the formation of a computer-based way in which the quality of the line (script) and its principles do not hurt and trustee of old fashion is essential.

\footnotetext{
${ }^{5}$ In the name of God the compassionate the merciful.
} 


\section{References}

Baratzadeh, Leily (2005). Calligraphy in Iran. Tehran: Cultural Studies Office.

Faraadi, Abdullah (1969). Farsi Line (script) 2, Kaveh Magazine (Munich) No. 24, August 1969.

Fazaeli, Habibollah (2008). Teaching Script, (10 ed.). Tehran: Soroush Publications.

Manavi Rad, Mitra (2006). Calligraphy Position in the Age of Technology. Moon Art, No. 95 \& 96, August 2006.

Nasr, Seyyed Hossein (2001). Knowledge and Spirituality, Translated by Enshallah Rahmati. Tehran: Sohrevardi Research and Publishing Office.

Pakbaz, Rooin (2004). Encyclopedia of Art (4 ${ }^{\text {th }}$ ed.). Tehran: Contemporary Culture.

Peasy, Arnold (1988). Technology and Culture ( $2^{\text {nd }}$ ed.). Tehran: Bahram Shalgoni Center Publication.

Rahbarnia, Zahra \& Rahnavard, Zahra (2006). Faces of Sacred Art with Technology, Fine Arts, No. 26, Summer 2006.

Rashvand, Ismail (2005). Calligraphy (textbooks). Tehran: Educational Research and Educational Organization.

Schimmel, Annemarie (1989). Calligraphy and Islamic Culture, Translated by Asadollah Azad. Mashhad: Astan Quds-Razavi Institute.

Teimoori, Kaveh (2010). New Approaches to Contemporary Iranian Calligraphy, Moon Art, No. 143, August 2010. 